\title{
Thermodynamic efficiency of carbon capture and utilisation in anaerobic batch digestion process
}

Sung T. Oh ${ }^{* l}$ and Alastair Martin ${ }^{2}$

${ }^{* 1}$ Department of Civil and Environmental Engineering, University of Abertay Dundee, DD1 1HG, United Kingdom;

${ }^{2}$ Department of Engineering, Lancaster University, Bailrigg, Lancaster, LA1 4YR, United Kingdom

AUTHOR EMAIL ADDRESS: ${ }^{* 1}$ s.oh@ abertay.ac.uk; ${ }^{2}$ a.martin1 @lancaster.ac.uk

\section{AUTHOR ADDRESS}

${ }^{* 1}$ Sung T. Oh

Department of Civil and Environmental Engineering, University of Abertay Dundee, Dundee, DD1 1HG, United Kingdom, Tel: +44 1382 308930; E-mail: s.oh@abertay.ac.uk

${ }^{2}$ Alastair D Martin

Department of Engineering, Lancaster University, Bailrigg, Lancaster, LA1 4YR, United Kingdom, Tel: +44 1524 592335; E-mail: a.martin1@lancaster.ac.uk 


\begin{abstract}
Carbon capture and storage (CCS) in the oil and water industries is becoming common and a significant consumer of energy typically requiring $150-450{ }^{\circ} \mathrm{C}$ and or several hundred bar pressure [1] particularly in geological deposition. A biological carbon capture and conversion has been considered in conventional anaerobic digestion processes. The process has been utilised in biological mixed culture, where acetoclastic bacteria and hydrogenophilic methanogens play a major key role in the utilisation of carbon dioxide. However, the bio catalytic microorganisms, hydrogenophilic methanogens are reported to be unstable with acetoclastic bacteria. In this work the biochemical thermodynamic efficiency was investigated for the stabilisation of the microbial process in carbon capture and utilisation. The authors observed that a thermodynamic efficiency of biological carbon capture and utilisation (BCCU) had $32 \%$ of overall reduction in yield of carbon dioxide with complimentary increase of $30 \%$ in yield of methane, while the process was overall endothermic. Total consumption of energy $\left(\approx 0.33 \mathrm{MJ}^{-1}\right)$ was estimated for the carbonate solubility $\left(0.1\right.$ mole $\left.^{-1}\right)$ in batched BCCU. This has a major influence on microbial composition in the bioreactor. This thermodynamic study is an essential tool to aid the understanding of the interactions between operating parameters and the mixed microbial culture.
\end{abstract}

\title{
KEYWORDS
}

Carbon Capture and Storage; Utilisation; Electrochemical Thermodynamics, Anaerobic Digestion;

\section{INTRODUCTION}

The UK emission of greenhouse gases has been slowly decreasing year by year; was estimated to be 569.9 million tonnes carbon dioxide equivalent (MtCO2e) annually [2] in 2013 whereas it was 777.12 MtCO2e [2] in 1990. The UK strategy of the greenhouse gas emissions seems to be almost achievable, which will reach by at least $80 \%$ reduction (from the 1990 baseline) by 2050 [3]. However the UK water and waste industry has produced approximately $6 \mathrm{MtCO} 2 \mathrm{e}$ [4] annually; of which $56 \%$ is in the result of wastewater treatment processes including sludge management: in particular activated sludge process [5]. In case of the Thames Water Plc. in London consumes 7.7 TWh [6] $(\approx 2.5 \mathrm{MtCO} 2 \mathrm{e}$ by conversion factor of industrial coal $)$ for wastewater treatment annually, which is approximately $2-5 \%$ of the whole UK national 
consumption of primary fuel. This is a disappointing result regardless of high efficiency of 'lowcarbon' technologies to compete internationally and generate economic growth.

As a direct in-door capture followed by storage technology, such as geological carbon capture and storage (CCS) or oceanic reservoirs, has been widely introduced for the UK water industry but it still has many difficulties to adapt the technology: long term operating and monitoring costs [7], significant risk of site-leaking [8], effective carbon capture and transport [9] from conventional activated sludge process. A biological carbon capture and conversion has been considered in existing and conventional anaerobic digestion process in water industry. Fernandez, et. al. [10] utilised anaerobic batched digestion process to observe maximum BCCU capacity and limitation/inhibition in range of the process capacity, which overall $\mathrm{CO}_{2}$ reductions are 3-34\% in anaerobic batched digestion process and $\mathrm{CH}_{4}$ yields are increased in range of 13-138\% Salomoni et. al. [11] also observed an extra $25-30 \%$ of methane $\left(\mathrm{CH}_{4}\right)$ yield in continuous twostage anaerobic digestion of sewage sludge. These results seem to be a promising technology in $\mathrm{CH}_{4}$ conversion from biological carbon capture and utilisation whilst, Oh et. al. [6] reported very low energy efficiency (5-15\%) of anaerobic digestion process itself and the biogas yield is less than $50 \%$ of carbonaceous feedstocks $[6,12]$ in heterogeneous domestic or municipal wastes. Moreover, Alimahmoodi and Mulligan [13] reported a 69-86\% efficiency of only aqueous $\mathrm{CO}_{2}$ uptake in an upflow anaerobic sludge blanket (UASB) reactor of food wastes. These observations directly tell us that biological carbon capture and utilisation (BCCU) is strongly limited by hydrogenophilic methanogens with a range of $\mathrm{CO}_{2}$ solubility, which is less than 1300 $\mathrm{mg}^{-1}$ of $\mathrm{CO}_{2}$ in diluted aqueous solution.

Biological $\mathrm{CO}_{2}$ capture is dependent on reversible or backward reaction by acetoclastic bacteria [14] under strong dissociation of $\mathrm{CO}_{2}$, meanwhile the utilisation relies on the microbial activity of hydrogenophilic methanogens. The two simultaneous reactions, both are thermodynamically spontaneous, competitive and exothermic, but rely on ' $\mathrm{H}_{2}$ partial pressure'. Moreover the utilisation is indirectly correlated to microbial relationship between acetoclastic methanogens and syntrophic acetogenic bacteria followed by fermentative bacteria. Oh and Martin [15] reported that the activity of acetoclastic methanogens is thermodynamically spontaneous $(\Delta G<0)$ but entirely endothermic process. The syntrophic acetogenic bacteria converting fermentation products into acetate and 'molecular $\mathrm{H}_{2}$ ' are not generally thermodynamically feasible biological reactions ( $\Delta G>>0$ ), only becoming feasible at very low ' $\mathrm{H}_{2}$ partial pressure' 
[16] in absence of acetoclastic conversions. The metabolic efficiency and the growth yield of the syntrophic acetogenic bacteria, depend strongly on the removal rate of the 'molecular $\mathrm{H}_{2}$ ' by a consuming species $[17,18]$.

Practically the 'molecular hydrogen' having very low solubility (Henry's law coefficient $8.58 \times$ $10^{-4} \mathrm{~mol} \mathrm{~atm}^{-1} \mathrm{l}^{-1}$ ) is spontaneously transferred into 'gas phase' and the 'partial pressure' is maintained in very low range of values (i.e. $\left.10^{-6}<\mathrm{H}_{2}(\mathrm{~atm})<10^{-4}\right)[17,18]$. The hydrogen transport between functional anaerobic microorganisms is almost impossible as a result of the hydrogen diffusion coefficient $\left(4.50 \times 10^{-9} \mathrm{~m}^{2} \mathrm{~s}^{-1}\right)$ [16], while 'transport of electrons and protons' has a feasibility to link metabolic pathway between functional anaerobic microorganisms. In case of anaerobic biofloc, microbial oxidising bacteria are continuously producing electrons and protons while microbial reductive bacteria are consuming them through hydrogen bonding structure in water $[15,16]$. In intrinsic distance between functional microorganisms such as fixed biofilm, the microorganisms produce biochemical mediators (i.e. $\mathrm{NAD}^{+} / \mathrm{NADH}$ ) for electrochemical salt bridge between functional microorganisms to electrical conduction of electrons and protons. This suggests that the electron/proton transport between functional microorganisms can occur independently of the conventional biochemical carriers but the success of the biological carbon capture and utilisation (BCCU) might be attributable to the efficiency of the proton/electron transport in microbial processes.

On this basis this work established the catabolic reactions completely linked between the microorganisms through proton/electron pairs, in terms of a couple of inter cellular mediator $\left(\mathrm{NAD}^{+} / \mathrm{NADH}\right)$. The overall process was thus assumed to be at the electrochemical equilibrium state whilst there is a quasi-steady state of microbial growth. The authors thermodynamically investigated the efficiency and the limitation of the BCCU in anaerobic digestion process. The resulting model is used to only investigate a magnitude of the thermodynamic driving force (i.e. $\Delta G, \Delta H$ and $\Delta S$ ) but overcome thermodynamic limitations leading to practical operation of biological carbon capture and utilisation (BCCU).

\section{MODEL DEVELOPMENT}

The biological carbon capture and utilisation (BCCU) is modelled and simulated in an isothermal and isobaric condition (298.15 $\mathrm{K}$ and $1 \mathrm{~atm})$ of anaerobic batch digester. The anaerobic digester 
is assumed to contain a 'fully acclimatised' fermentative bacteria, syntrophic acetogenic bacteria, acetoclastic bacteria and methanogenic consortium with anaerobic ammonium oxidising bacteria. A two-phase digester is assumed: gas and solution.

In this case, the authors propose the addition of carbon dioxide into the two-phase digester for a BCCU and then an intensive biogas. The initial substrate is the aqueous form of carbon dioxide (aqueous $\left.\mathrm{CO}_{2}\right)$ in the constant moles of glucose $(0.1,1$ and 10 mmoles). Initial moles (10 mmole $)$ of glycerol $\left(\mathrm{C}_{3} \mathrm{H}_{8} \mathrm{O}_{3}\right)$ and ethanol $\left(\mathrm{C}_{2} \mathrm{H}_{6} \mathrm{O}\right)$ are also constantly injected, where 10 mmole of aqueous ammonia $\left(\mathrm{NH}_{3}\right)$ is assumed in approximately range $10-250$ mmole $1^{-1}$ as mixed sewage sludge $[19,20] .1$ mmole of NADH is considered as a biochemical hydrogen mediator to trade-off hydrogen molecule between micro-organisms. The authors consequently investigate sensitive changes ( $\Delta \mathrm{E}, \Delta \mathrm{H}$ and $\Delta \mathrm{S})$ in electrochemical equilibrium state $(\Delta \mathrm{G}=\mathrm{zero})$ at conserved system mass (one kilogram). As the initial mole fraction of aqueous carbon dioxide $\left(x=\mathrm{CO}_{2} /\left(\mathrm{H}_{2} \mathrm{O}+\mathrm{CO}_{2}+\mathrm{NH}_{3}+\mathrm{C}_{2} \mathrm{H}_{6} \mathrm{O}+\mathrm{C}_{6} \mathrm{H}_{12} \mathrm{O}_{6}+\mathrm{TNADH}\right)\right)$ is increased, the moles of solvent water $\left(\mathrm{H}_{2} \mathrm{O}\right)$ is reduced. This is based on the mass conservation of system (one kilogram). In regarding different conditions (i.e. feeding concentration of $\mathrm{CO}_{2}$ ), it is also investigated how the deviation has an influence on the sensitive changes $(\Delta \mathrm{E}, \Delta \mathrm{H}$ and $\Delta \mathrm{S})$ and then how they can affect BCCU. Although the authors theoretically investigate in the whole range of initial $\mathrm{CO}_{2}$ mole fraction $(0<x<0.93)$ in the conserved mass $(1 \mathrm{~kg}$ of three phased batch reactor), where the high range of initial $\mathrm{CO}_{2}$ mole fraction $(x>0.0005)$ has practically been operated $[10,11]$. Furthermore, the low range of initial $\mathrm{CO}_{2}$ mole fraction $(x<0.0005)$ is also included in the case of an sequencing injection as a solid or gaseous forms of $\mathrm{CO}_{2}$.

The thermodynamic model comprises three parts of equilibrium state (phase transition, dissociation and electrochemical reaction) on quasi steady state of growth rate in microorganisms. The first includes equilibrium expressions that relate the relative aqueous activities and vapour fugacities of all chemical species in the two-phased digestion process. The second consists of the dissociation/association that quantifies the relationships between cation activity and anion activity in the liquid phase. The third consists of the reduction and oxidation state that based on the electrochemical potential (V) through NAD+/NADH ratio. The completed model consists of a set of highly non-linear simultaneous equations which was solved using Newton-Raphson Algorithm [15] based on the Jacobian matrix. 


\subsection{Stoichiometric relationships of carbon capture and utilisation}

The stoichiometric expressions are established in the common manner to quantify the feasible relationships between the initial substrate and the products and the intermediates. Table 1 shows the stoichiometric relationship for BCCU in anaerobic sludge digestion. The stoichiometric relationships are categorised by three equilibrium relationships which are electrochemical reaction, two-phase transition and electrolyte ionisation reaction.

\section{<TABLE 1>}

\subsection{Equilibrium relationships of carbon capture and utilisation}

This model from the stoichiometric foundations is developed using the fundamental definition of thermodynamic chemical equilibrium.

$$
\sum v_{i} \mu_{i}=0
$$

where $v_{i}$ is stoichiometric coefficient of component $i$ and the chemical potential $\mu_{i}$ is expressed as the standard chemical potential $\mu_{i}^{\circ}$ and activity $a_{i}$ of component $i$.

$$
\mu_{i}=\mu_{i}^{\circ}+R T \ln a_{i}
$$

where $R$ is universal gas constant and $T$ is absolute temperature.

\subsubsection{Vapour and Liquid Equilibria}

Vapour and liquid equilibria relevant to the BCCU are developed in conventional anaerobic sludge digestion process. Butanol, propanol, glycerol and ethanol are considered as non-volatile due to the very low Henry's coefficients. Butyric, propionic and acetic acids are also non-volatile and therefore only nitrogen, hydrogen, ammonia, carbon dioxide, methane and water are able to exist in gaseous phase. Henry's law coefficients relevant to the anaerobic batch digester are shown in Oh and Martin [15]. Table 2 shows the stoichiometric foundations and their chemical equilibrium constants and their numerical relationships are governed by Equation (1).

$<$ TABLE 2>[21-24] 


\subsubsection{Electrolyte Ionisation Equilibrium}

Carbonates are highly dissociated and structured with other ionic chemical species in the liquid aqueous phase, that is strongly depended on the equilibrium concentration of protons $\left[\mathrm{H}^{+}\right]$; $\mathrm{pH}$ value. The authors modelled the ionic structure of the carbonates linked to the vapour phase equilibrium, which affects to the chemical potential $\mu_{i}$ of the chemical component $i$.

$$
\begin{gathered}
v_{i} \mu_{i}=v_{j} \mu_{j}^{+}+v_{k} \mu_{k}^{-} \\
K_{a}=\exp \left\{\frac{v_{i} \mu_{i}^{\circ}-v_{j} \mu_{j}^{\circ+}-v_{k} \mu_{k}^{\circ-}}{R T}\right\}=\frac{\left(a_{j}^{+}\right)^{v_{j}}\left(a_{k}^{-}\right)^{v_{k}}}{a_{i}^{v_{i}}}
\end{gathered}
$$

Substituting Equation (2) into Equation (3) yields the ionisation relationship, where equilibrium constant corresponds to dissociation constants $K_{a}$ of the carbonates in anaerobic sludge digesters. Table 3 shows the stoichiometric foundations and their chemical equilibrium constants and mathematic relationships which are based on Equation (4). In this research, it is a key player that carbonates react with existing ammonium ions; then they are solidificated into ammonium salts $\left(\left(\mathrm{NH}_{4}\right) \mathrm{HCO}_{3},\left(\mathrm{NH}_{4}\right)_{2} \mathrm{CO}_{3}, \mathrm{C}_{2} \mathrm{H}_{3} \mathrm{O}_{2}\left(\mathrm{NH}_{4}\right), \mathrm{C}_{3} \mathrm{H}_{5} \mathrm{O}_{2}\left(\mathrm{NH}_{4}\right), \mathrm{C}_{4} \mathrm{H}_{7} \mathrm{O}_{2}\left(\mathrm{NH}_{4}\right)\right.$ and $\left.\mathrm{NH}_{4} \mathrm{NO}_{3}\right)$ in the $\mathrm{BCCU}$ in anaerobic sludge digestion process.

\section{<TABLE 3>}

\subsubsection{Electrochemical Equilibrium between Microorganisms}

Biological electrochemical equilibrium is, in particular, described in the form of coupled half electrochemical reactions linked through the biological mediator ( $\left.\mathrm{NAD}^{+} / \mathrm{NADH}\right)$. The half electrochemical reactions occur by coupled oxidation and reduction (redox), so that the electron released by one reactant is accepted by another. Here, the authors assumed that reduction and oxidation potentials are reached very fast to the 'equilibrium state' of BCCU. The half reactions and equilibrium relationships relevant to acetoclastic methanogens and syntrophic acetogenic bacteria were developed in Oh and Martin [15, 16, 25, 26]. The half reactions and equilibrium relationships relevant to fermentative bacteria, hydrogenophilic methanogens and anaerobic ammonium oxidising bacteria were developed in Oh and Martin [16] and are used here without modification. An example of hydrogenophilic methanogens is given by 
Oxidation $\mathrm{NADH}+\mathrm{H}^{+} \leftrightarrows \mathrm{NAD}^{+}+2 \mathrm{H}^{+}+2 \mathrm{e} \mathrm{e}^{-}$

Reduction $\quad \mathrm{CO}_{2}(\mathrm{aq})+8 \mathrm{H}^{+}+8 \mathrm{e}^{-}=\mathrm{CH}_{4}(\mathrm{aq})+2 \mathrm{H}_{2} \mathrm{O}(\mathrm{l})$

Leading to the overall redox reaction,

$\mathrm{CO}_{2}(\mathrm{aq})+4 \mathrm{NADH}+4 \mathrm{H}^{+}=4 \mathrm{NAD}^{+}+\mathrm{CH}_{4}(\mathrm{aq})+2 \mathrm{H}_{2} \mathrm{O}(\mathrm{l})$

Acetoclastic bacteria is given by

Oxidation $\quad \mathrm{C}_{2} \mathrm{H}_{4} \mathrm{O}_{2}(\mathrm{aq})+2 \mathrm{H}_{2} \mathrm{O}(\mathrm{l})=2 \mathrm{CO}_{2}(\mathrm{aq})+8 \mathrm{H}^{+}+8 \mathrm{e}^{-}$

Reduction $\quad 2 \mathrm{H}^{+}+2 \mathrm{e}^{-}+\mathrm{NAD}^{+}=\mathrm{NADH}+\mathrm{H}^{+}$

Leading to the overall redox reaction,

$\mathrm{C}_{2} \mathrm{H}_{4} \mathrm{O}_{2}(\mathrm{aq})+4 \mathrm{NAD}^{+}+2 \mathrm{H}_{2} \mathrm{O}(\mathrm{l})=2 \mathrm{CO}_{2}(\mathrm{aq})+4 \mathrm{NADH}+4 \mathrm{H}^{+}$

Anaerobic ammonium oxidising bacteria is given by

Oxidation $\quad 2 \mathrm{NH}_{3}(\mathrm{aq})=\mathrm{N}_{2}(\mathrm{aq})+6 \mathrm{H}^{+}+6 \mathrm{e}^{-}$

Reduction $\quad 2 \mathrm{H}^{+}+2 \mathrm{e}^{-}+\mathrm{NAD}^{+}=\mathrm{NADH}+\mathrm{H}^{+}$

Leading to the overall redox reaction,

$2 \mathrm{NH}_{3}(\mathrm{aq})+3 \mathrm{NAD}^{+}=3 \mathrm{NADH}+3 \mathrm{H}^{+}+\mathrm{N}_{2}(\mathrm{aq})$

Fermentative bacteria is given by

Oxidation $\mathrm{NADH}+\mathrm{H}^{+} \leftrightarrows \mathrm{NAD}^{+}+2 \mathrm{H}^{+}+2 \mathrm{e}^{-}$

Reduction $\quad \mathrm{C}_{6} \mathrm{H}_{12} \mathrm{O}_{6}(\mathrm{aq})+4 \mathrm{H}^{+}+4 \mathrm{e}^{-}=\mathrm{C}_{4} \mathrm{H}_{8} \mathrm{O}_{2}(\mathrm{aq})+\mathrm{C}_{2} \mathrm{H}_{4} \mathrm{O}_{2}(\mathrm{aq})+2 \mathrm{H}_{2} \mathrm{O}$

Leading to the overall redox reaction,

$\mathrm{C}_{6} \mathrm{H}_{12} \mathrm{O}_{6}(\mathrm{aq})+2 \mathrm{NADH}+2 \mathrm{H}^{+}=2 \mathrm{NAD}^{+}+\mathrm{C}_{4} \mathrm{H}_{8} \mathrm{O}_{2}(\mathrm{aq})+\mathrm{C}_{2} \mathrm{H}_{4} \mathrm{O}_{2}(\mathrm{aq})+2 \mathrm{H}_{2} \mathrm{O}$ $\sum_{k} v_{k} \mu_{k}+n e^{-}=0$

$\sum_{j} v_{j} \mu_{j}-n e^{-}=0$

$$
\sum_{k} v_{k} \mu_{k}+\sum_{j} v_{j} \mu_{j}=0
$$

$\sum_{k} v_{k} \mu_{k}+n e^{-}=0$

$\sum_{l} v_{l} \mu_{l}-n e^{-}=0$

$$
\sum_{k} v_{k} \mu_{k}+\sum_{l} v_{l} \mu_{l}=0
$$

$\sum_{k} v_{k} \mu_{k}+n e^{-}=0$

$\sum_{l} v_{l} \mu_{l}-n e^{-}=0$

$\sum_{k} v_{k} \mu_{k}+\sum_{l} v_{l} \mu_{l}=0$

$\sum_{i} v_{i} \mu_{i}+n e^{-}=0$

$\sum_{j} v_{j} \mu_{j}-n e^{-}=0$

$\sum_{i} v_{i} \mu_{i}+\sum_{j} v_{j} \mu_{j}=0$

where, the pair of half reactions should be in a state of equilibrium, the equilibrium relation is defined by the equality of the pairs of the electrochemical potentials $E(V)$.

$$
\sum v_{i} \mu_{i}=n F E_{i}(V)
$$

Where, $F$ is the Faraday's constant and $n$ is the numbers of electrons transferred. The relationship between the chemical activity $a_{i}$ and electrochemical potential $\mathrm{E}(\mathrm{V})$ for the $i$ th half reaction is shown in Equation (6):

$$
n F E_{i}=\sum v_{i} \mu_{i}^{\circ}+R T \sum v_{i} \ln a_{i}
$$


Thus, the electrochemical equilibrium is established by the equality of electrochemical potentials and it is corresponding to the equilibria on the pairs of half REDOX reactions.

$$
E_{i}=E_{j}=E_{k}=E_{l}=\cdots
$$

This electrochemical equilibrium relationship (Equation 7) allows to couple of transportation energy between functional micro-organisms in BCCU. This directly represents a synthesis of organic carbons from the injected inorganic carbonates and is able to identify an elongation of carbon-chain numbers. Table 4 shows the half reactions representing microbial reactions of BCCU.

$<$ TABLE 4>[21]

\subsection{Relationship of activity and fugacity with concentration and partial pressure}

\subsubsection{Aqueous phase}

Activity $a_{i}$ and observable concentration $m_{i}$ is related by an activity coefficient $\gamma_{i}$ [27]. In a non-diluted solution in range of a mole fraction of carbonates $(x>0.0005)$, there are three types of model for the description of the activity coefficients that can be considered: Ideal model; Debye-Hückel model and Pitzer model. These models are equivalent to the 'conventional equations of state' used to quantify the analogous relationships in the gas phase and have limited ranges of applicability related to the ionic strength of the aqueous phase. These limitations together with their respective models for activity coefficients are discussed in Oh and Martin [15, 16]. Their parameter values are re-used in this work.

$$
a_{i}=\gamma_{i} m_{i}
$$

\subsubsection{Gaseous phase}

Fugacity $f_{i}$ is related to observable partial pressure $y_{i} P$, in a manner analogous, to activity and concentration in solution phase through the fugacity coefficient, $\Phi_{i}$.

$$
f_{i}=\Phi_{i} y_{i} P
$$


Where, fugacity coefficient $\Phi_{i}$ can be derived from a suitable equation of state (EoS). Oh and Martin [15] used the Nakamura et al. EoS [28] to describe the mixture of non-polar and polar gases found in BCCU. This work uses the same EoS, thus ensuring consistency between the results.

\subsection{Overall phase and mass balances}

The equilibrium model requires a strict mass balance condition. The components of overall balances were constituted for the i) vapour phase, ii) solute and iii) pure water from the stoichiometric model.

$$
N \sum_{i} y_{i} M_{W i}+\frac{\operatorname{Re}(W)}{55.494} \sum_{i \neq H_{2} O} m_{i} M_{W i}+18.02 \operatorname{Re}(W)=1000(g)
$$

Where the $N$ is total mole of vapour phase in the digestion system. The $M_{W i}$ is the molecular weight of chemical species $i$. The $\operatorname{Re}(W)$ is the moles numbers of water in solution, which the total mass of system is conserved to one kilogram. Strict element material balances: carbon, hydrogen, oxygen and nitrogen, are also considered.

The vapour balance, liquid balance and charge balance are considered at the state of equilibrium.

$$
\begin{aligned}
& \sum_{i} y_{i}=1 \\
& \sum_{i} x_{i}=1 \\
& \sum_{i} z_{i} m_{i}=\text { zero }
\end{aligned}
$$

where $x_{i}$ and $y_{i}$ are the mole fractions of $i^{\text {th }}$ component in liquid and vapour phase respectively. $z_{i}$ is the number of charge in liquid phase.

\section{RESULTS AND DISCUSSION}




\subsection{Enthalpy and entropy analysis in biogas formation}

For quantifying the overall process performance, biogas production is quantitatively measured. Figure 1a shows a plot of biogas production versus $\mathrm{CO}_{2}$ mole fraction, $x$, whereas $x$ is increased the gas phase increases and symmetrically reduces liquid phase. This is due to the conservation of mass in $1 \mathrm{~kg}$ of system. This implies that $x$ of a digester feed should be maximised within operating constraints such as pumpability or carbonaceous inorganic loading rate. Practically this limits $x$ to values higher than 0.0005 which is equivalent nominal $\mathrm{CO}_{2}$ feed of 0.035 mole $1^{-1}$ (aqueous $\mathrm{CO}_{2}$ solubility). This work also shows the results of a set of high concentration cases $(0.0005<x<0.98)$ in which the water is progressively consumed until it is completely exhausted. In the high concentration of $x$, organic carbons are almost completely converted into $\mathrm{CO}_{2}$ and $\mathrm{CH}_{4}$, and then vaporised.

\section{$<$ FIGURE 1 $>$}

In thermodynamic point of view, Oh and Martin [15, 16] reported that individual glucose fermentation is spontaneous to forward direction $(\Delta G<0, \Delta H<0$ ), but individual ethanol fermentation and syntrophic acetogenesis are nonspontaneous $(\Delta G>0, \Delta H>0)$ requiring thermal energy to forward direction. Independent acetoclastic methanogenesis is also entirely endothermic due to the vaporisation of $\mathrm{CH}_{4}$ and $\mathrm{CO}_{2}$. The whole glucose-ethanol mixed sludge digestion is able to proceed when the nonspontaneous ethanol fermentation is metabolically coupled with the glucose fermentation by $\mathrm{NAD}^{+} / \mathrm{NADH}[16]$. Figure $1 \mathrm{~b}$ shows a plot of enthalpy changes $\Delta H$ of whole process versus $\mathrm{CO}_{2}$ mole fraction, $x$. In low range of $x(<0.0005) \Delta H$ has constantly negative small amount of value, which indicates exothermic process until $\mathrm{CO}_{2}$ is fully saturated in aqueous phase. The negative value also indicates us that the 'glucose-ethanol fermentation' is able to produce great heat energy more than the following methanogenic process. The result is corresponding to the work of Oh and Martin [16], which reported that fermentative bacteria play a key role in anaerobic sludge digestion. In particular high range of $x$, as the $x$ is increased, overall $\Delta H$ becomes zero at $x(\approx 0.005)$ and then it is continuously increased to relatively higher endothermic. The results tell us that the $\mathrm{CO}_{2}$ solubility is increased in one order of magnitude from aqueous solubility $(x \approx 0.0005)$ to mixture solubility $(x \approx 0.005)$ as $\mathrm{CO}_{2}$ is dissociated in anaerobic digestion process. This is attributed to the equation of state (EoS) relationship between $\mathrm{pH}$ value and partial pressure of carbon dioxide. In thermodynamic basis, it 
implies that the amount of $\mathrm{CO}_{2}$ captured cannot be greater than 0.1 mole $1^{-1}$ (i.e. 2.241 of $\mathrm{CO}_{2}$ gas) of batch digestion liquor at 1atm and 298 K. Practically Alimahmoodi and Mulligan [13] achieved $69-86 \%$ of aqueous $\mathrm{CO}_{2}$ uptake in an upflow anaerobic sludge blanket (UASB) reactor of food wastes, the BCCU can be theoretically achieved in range of 3000-3500 $\mathrm{mg}^{-1}$ in which strongly limited by the solubility. This is a significant result in comparison with $\mathrm{CO}_{2}$ aqueous solubility; $1540 \mathrm{mg} \mathrm{l}^{-1}$. The process is anticipated to produce a various salts of carbonates. It is directly related to the $\mathrm{pH}$ inhibition and the limitation of ammonium oxidation which will be explained in next sections.

In entropy analysis, $\Delta S$ has the same tendency as the change in $\Delta H$ at equilibrium state ( $\Delta G=$ zero). The BCCU in digestion process exhibits constantly negative small value of $\Delta S$ in low range of $x(<0.005)$. This result tells us that a dissociation of inorganic carbon $\left(\mathrm{CO}_{2}\right)$ may be a major driving force for the reduction of molecule disorder, but thermodynamically nonspontaneous. In high range of $x(>0.005)$, as $x$ is increased, the entropy change is continuously increased to positive value in the range of higher concentrations from the saturated $\mathrm{CO}_{2}$ concentration. In process control point of view, the thermodynamic study tells us that a high concentration of $\mathrm{CO}_{2}$ feedstock is initially dissociated as long as consuming thermal energy and then the BCCU is increased as much as the reduction of vapour phase, which would be based on the zero-order kinetics. In a long term batch operation, the overall process becomes thermodynamically unfavourable and instantly stops once the $\mathrm{CO}_{2}$ is unsaturated in the liquor, approximately $x \approx 0.005\left(0.1\right.$ mole $\left.1^{-1}\right)$.

\subsection{Biosynthesis of volatile fatty acids}

Residual glucose has numerically very small values. The intermediates, volatile fatty acids (butyric, propionic and acetic acids) and primary alcohols (ethanol, propanol, glycerol and butanol), are produced from the BCCU. The intermediates also have very small values in magnitude throughout the whole range of initial mole fraction $(x)$ of carbon dioxide investigated. This means that in the presence of acetoclastic methanogens an accumulation of acetic acid is not favourable over a wide range of carbonate concentrations $x$. However dual-carbon (equilibrium concentration of acetate + ethanol) is consistently shown in the highest organic concentration in the digested liquor. Figure 2a shows that as $x$ is increased, a yield of dualcarbon $(\mathrm{C} 2)$ decreases from various values of glucose feedstocks and become a constant value at 
$x=0.005$. In high range of $x(>0.005)$ as $x$ is increased, the $\mathrm{C} 2$ yield continuously decreases. This result shows us that, regardless of acetoclastic methanogenesis, acetoclastic oxidation by acetolcastic bacteria is against Le Chatelier's principle, which is attributed to the methanogenic activity of hydrogenophilic methanogens promoting an acetoclastic oxidation by acetoclastic bacteria. The model result is in good agreement with Kim's observations [29, 30]. Their first observation was that the utilisation of acetate increased as the $\mathrm{pCO}_{2}$ (partial pressure) was slightly increased (0.5-0.6 atm) [30]. They also showed a reduction in methane production rate with an increase of $\mathrm{pCO}_{2}(>0.7 \mathrm{~atm})$. The results of this modelling work support a thermodynamic explanation of Kim and Noike's, and Kim and Lee's observations. Their observed inhibition of methane formation can be correlated to a change in the position of chemical equilibrium, which results from the depletion of the proton arising from the solubility of $\mathrm{CO}_{2}$ in the liquor. However in this model of glucose digestion, the $\mathrm{pH}$ value is almost constant in low range of $x$ as shown in figure $3 \mathrm{c}$ and the $\mathrm{C} 2$ yield is almost a plat in the same ranged area of low range of $x(<0.005)$. This tells us that regardless of favourable fermentation process, syntrophic acetogenic process decomposing ferment products compensate acetate and proton from the overall depletion in overall process. This can be also attributable to the association of ammonium ion with carbonate resulting in product-inhibition of acetoclastic oxidation and it will be clearly explained in ammonium oxidation section. In the same ranged area of low range of $x(<0.005)$, figure $2 \mathrm{a}$ also shows that a vertical deviation from 0.1 mmole glucose feedstock at constant $x$, represents a difference of molecular composite from the initial glucose feedstock. The deviation approximates one orders of magnitude corresponding to around $0.5 \mathrm{mg} \mathrm{l}^{-1}$ as acetate. In the high range of $x(>0.005)$ the vertical deviation is vanished at $x=0.005$. It show us that a glucose utilisation to acetate in low range of $x$, is against Le Chatelier's principle. It was also explained in previous section. This interaction of microbial consortia will be clearly explained with proton concentration (equilibrium $\mathrm{pH}$ ) in next section.

\section{$<$ FIGURE 2>}

Here the authors are interested in a yield of mono-carbon by comparing with a yield of dual carbons. Figure $2 \mathrm{~b}$ shows that a yield of mono-carbon $\left(\mathrm{CH}_{4}+\mathrm{CO}_{2}\right)$ increases from various values of glucose feedstocks to one as $x$ is increased. The yield $(=1)$ represents that total numbers of carbons in feedstock completely is degraded into mono-carbons, whilst, in low range of $x(<0.005)$, a lower yield $(<1)$ represents that long chain carbons can be produced in aqueous 
phase. The deviation from one is vertically maximised up to $3 \times 10^{-7}$ [mole mole ${ }^{-1}$ corresponding to around $3 \mathrm{mg} \mathrm{kg}^{-1}$ of molecular carbon, which is almost symmetrically consistent with the $\mathrm{C} 2$ yield of molecular carbons. This is also consistent with the negative entropy changes shown in figure 1b. In a long term operation of the BCCU, the thermodynamic basis shows us that a BCCU converting carbonates to acetate is strongly favourable in low range of $x$, while the product seems to be degraded through acetoclastic methanogenesis and then the overall concentration is consistently very low.

\section{$3.3 \mathrm{pH}$, solubility and partial pressure}

Overall performance of $\mathrm{BCCU}$ can be estimated by a quantitative analysis of biogas i.e. $\mathrm{CH}_{4}$ partial pressures. Figure $3 \mathrm{a}$ shows a plot of partial pressures of $\mathrm{CH}_{4}$ and $\mathrm{CO}_{2}$ (i.e. $\mathrm{pCH}_{4}$ and $\mathrm{pCO}_{2}$ ) in the gas phase. As $x$ is increased, $\mathrm{pCH}_{4}$ is continuously decreased from various equilibrium values of glucose feedstocks, meanwhile $\mathrm{pCO}_{2}$ is symmetrically increased in the whole range of $x$. In low range of $x(<0.001)$ the $\mathrm{pCH}_{4}$ always higher than $\mathrm{pCO}_{2}$ due to the very high relative solubility of $\mathrm{CO}_{2}$. Figure $3 \mathrm{~b}$ also shows a mole distribution of $\mathrm{CO}_{2}$ between the phases. As $x$ is increased, the mole distribution tends to the gas phase, due to the $\mathrm{pH}$ dependency of $\mathrm{CO}_{2}$ solubility. These results are consistent with the overall phase distribution (biogas production) shown in figure 1a. Figure $3 \mathrm{~b}$ also shows that the $\mathrm{CO}_{2}$ distribution has constant values in the low range of $x(<0.0005)$ and then as $x$ is increased it is linearly increased from $x(>0.005)$ through the mid-range of $x(0.0005<x<0.005)$. This is mainly attributable to the 'unbalanced proton concentration (i.e. equilibrium $p H$ value)' between microbial consortiums.

\section{$<$ FIGURE 3>}

Figure 3c shows a plot of equilibrium $\mathrm{pH}$ values against $\mathrm{CO}_{2}$ mole fractions $(x)$ of feedstock in BCCU. As $x$ is increased, the equilibrium $\mathrm{pH}$ value has almost constant values in low range of $x(>0.0005)$ and then it has a trend decreasing from various constant equilibrium $\mathrm{pH}$ values of glucose feedstocks to the constant $\mathrm{pH}$ value $(\approx \mathrm{pH} 5.2)$ until the aqueous phase is vanished. In overall process, it tells us that, as $x$ is increased, nonspontaneous acetoclastic oxidation process $(\Delta \mathrm{G}>0$ and $\Delta \mathrm{H}>0$ ) decomposing acetate are loosely coupled with spontaneous hydrogenophilic methanogenesis $(\Delta \mathrm{G}<0$ and $\Delta \mathrm{H}<0)$ requiring protons and the process are slowly linked to 
spontaneous fermentative process requiring protons then the $\mathrm{pH}$ value is slowly decreased. Once ammonium oxidising process is also coupled to the fermentative process, the $\mathrm{pH}$ value is dramatically decreased from $x>0.005$ in high range of $x$. The result is consistent with methane yield shown in figure $3 \mathrm{~d}$. Figure $3 \mathrm{c}$ also shows that a vertical difference of the equilibrium $\mathrm{pH}$ values from 0.1 mmole of glucose feedstocks represents the great production of protons at constant $x$, while in high range of $x(>0.005)$, the equilibrium $\mathrm{pH}$ value has a constant value with the equilibrium $\mathrm{pH}$ value of 0.1 mmole of glucose digestion. This tells us that regardless of methanogenic processes, the fermentative process requiring protons coupled with the nonspontaneous syntrophic acetogenic process $(\Delta \mathrm{G}>0$ and $\Delta \mathrm{H}>0)$, is polygamous relationship to acetoclastic oxidation process $(\Delta \mathrm{G}>0$ and $\Delta \mathrm{H}>0)$ having a strong relationship with spontaneous hydrogenophilic methanogenesis $(\Delta \mathrm{G}<0$ and $\Delta \mathrm{H}<0)$ in low range of $x$. This is supported by $\mathrm{C} 2$ yield shown in figure $2 \mathrm{a}$. Even though ammonium oxidising process is also coupled to the fermentative process, the $\mathrm{pH}$ also becomes constant value in the low range of $x<0.005$.

Here the authors are very interested in the yields of methane to integrate between the microbial activities. Figure $3 \mathrm{~d}$ shows a proportional plot of $\mathrm{CH}_{4}$ yield over $\mathrm{CO}_{2}$ yield versus $\mathrm{CO}_{2}$ mole fraction of feedstock. As $x$ is increased, the proportion $\left(\mathrm{CH}_{4}: \mathrm{CO}_{2}\right)$ decreases from various relative high values corresponding to the molecular carbon oxidation in the redox state, to 1 at $x=0.0005$ and then it is continuously decreased. The proportion $(=1)$ represents that acetoclastic methanogens equally produce methane and carbonate $(1: 1)$. In the same ranged area of low range of $x(<0.0005)$, the greater proportions $(>1)$ represent that a metabolic pathway is consistent with that of microbial consortium at the proportion $(=1)$, but hydrogenophilic methanogens utilising carbon dioxide, protons and electrons, contribute to increase the great proportion $\left(\mathrm{CH}_{4}: \mathrm{CO}_{2}\right)$. In the high range of $x(>0.0005)$, the relative low proportions $\left(\mathrm{CH}_{4}: \mathrm{CO}_{2}\right)$ are attributed to the over saturated $\mathrm{CO}_{2}$ in the solution. It tells us that the oversaturation readily inhibit acetoclastic oxidation and then release the hydrogenophilic methanogens from the microbial consortium, while the anaerobic ammonium oxidising bacteria are strongly linked to fermentative bacterial consortium due to the highly decrease the $\mathrm{pH}$ value shown in figure $3 \mathrm{c}$.

\subsection{Anaerobic ammonium oxidation}

Partial pressure of ammonia $\left(\mathrm{pNH}_{3}\right)$ has very low value as low as empirically unobservable [31], which is due to that ammonium ion $\left(\mathrm{NH}_{4}{ }^{+}\right)$is thermodynamically favourable in the neutral range 
of $\mathrm{pH}$ value $(5<\mathrm{pH}<7)$ shown in figure $3 \mathrm{c}$. Figure $4 \mathrm{a}$ shows a partial pressure of nitrogen $\left(\mathrm{pN}_{2}\right)$ which is also very low in overall process. It tells us that both $\mathrm{pCO}_{2}$ and $\mathrm{pCH}_{4}$ are strongly favourable rather than $\mathrm{pN}_{2}$ and or $\mathrm{pNH}_{3}$ in the neutral range of $\mathrm{pH}(5<\mathrm{pH}<7)$ as shown in figure 3a. As $x$ is increased, the $\mathrm{pN}_{2}$ decreases from various value of feedstock to constant value $\left(3 \times 10^{-3}[\mathrm{~atm}]\right)$ at $x=0.005$ and then continuously decreases up to almost zero. It tells us that a mechanism of ammonium oxidation in the overall BCCU process seems to be shifted between low and high range of $x$, at $x=0.005$.

\section{<FIGURE 4>}

Figure $4 \mathrm{~b}$ shows an anaerobic ammonium oxidation of BCCU. As $x$ is increased in low range of $x(<0.001)$, ammonium oxidation slightly decreased, which is due to the $\mathrm{pH}$ inhibition. This result is also consistent with the negative change of entropy $(\Delta S)$ shown in figure $1 \mathrm{~b}$. Figure $1 \mathrm{~b}$ also showed that as $x$ is continuously increased, the entropy $(\Delta \mathrm{S})$ becomes zero at $x=0.005$, the metabolism is shifted to positive entropy $(\Delta S)$. This result is consistent with the work of Oh and Martin [31]. In the same ranged area of high range $x(>0.005)$, figure $4 \mathrm{~b}$ shows that, as $x$ is increased, anaerobic ammonium oxidation is dramatically increased, meanwhile the equilibrium of $\mathrm{pH}$ value is decreased in the same ranged area shown in figure $3 \mathrm{c}$. This result is partially consistent with the work of Oh and Martin [26] that hydrogenophilic methanogenesis has readily consorted with anaerobic ammonium oxidising bacterial consortium to produce methane. This appears in the whole process but it is clearly observed in case of low range of $x$. Thus, it implies us that, nonspontaneous ammonium oxidation is metabolically coupled with spontaneous fermentative reduction according as the carbonate inhibition of hydrogenophilic methanogenesis in the high range of $x$. Alternatively this observation can be explained by accumulation of ammonium salt $\left(\mathrm{NH}_{4} \mathrm{HCO}_{3}\right)$ with bicarbonate ion. The accumulation of ammonium bicarbonate has not only an negative influence on cell wall [32] but also makes entirely inhomogeneous process in low range of $x$. Figure $4 \mathrm{c}$ shows that a concentration of ammonium bicarbonate of BCCU in anaerobic digestion process is slightly increased as $x$ is increase, but it dramatically decreases unless the $\mathrm{pCH}_{4}$ is greater than $\mathrm{pCO}_{2}$ in high $x(>0.001)$. It tells us that the production of ammonium bicarbonate can be considerably related to the $\mathrm{pCO}_{2}$ rather than $\mathrm{pNH}_{3}$. However, figure $4 \mathrm{~d}$ shows that the accumulation of ammonium salt $\left(\mathrm{NH}_{4} \mathrm{HCO}_{3}\right)$ is limited by a decrease of water activity. It tells us that a production of ammonium bicarbonate adjusts amount of ammonium oxidation but water activity increase the accumulation. In operating point of view, 
ammonium ion resulting from degradation of proteins or meat processing can be easily converted to nitrogen once water activity is lower than 1, while it can be limited in approximately mix. $10 \%$ of ammonium oxidation, it is due to the presence of $\mathrm{NH}_{4} \mathrm{HCO}_{3}$ in water activity, 1 .

In microbiological point of view, fermentative bacteria loosely coexist with syntrophic acetogenic bacteria in where the acetoclastic methanogens are strongly linked. In particular low range of $x(<0.005)$, the spontaneous hydrogenophilic methanogens strongly collaborate with acetoclastic bacteria for the production of methane, and then the nonspontaneous acetoclastic bacteria is driven to the forward direction producing proton and electron. The hydrogenophilic methanogens also collaborate with anaerobic ammonium oxidising bacteria for the same purpose of methane production. This result is supported by the previous work of Oh and Martin [26] that bacterial consortium of anaerobic ammonia oxidising bacteria and hydrogenophilic methanogens is coexisting in absence of fermentative bacteria. However the carbonates concentration is over saturated in solution phase, such as high range of $x(>0.005)$, an productinhibition of acetoclastic bacteria drive that the anaerobic ammonium oxidising bacteria change their partner from hydrogenophilic methanogens to fermentative bacteria and the methanogenic activity of hydrogenophilic methanogens is vanished. Thus the fermentative bacteria have a polygamous relationship between syntrophic acetogenic bacteria, acetoclastic bacteria and anaerobic ammonium oxidising bacteria. The observation appears to be conventional glycolysis pathway in high range of $x(>0.005)$, which is supported by the data in figure $2 \mathrm{a}, 2 \mathrm{~b}, 3 \mathrm{c}$ and $3 \mathrm{~d}$. Figure $5 \mathrm{a}$ and $5 \mathrm{~b}$ shows the two cases of simple diagrams based on relative enthalpy versus reaction coordinates.

\section{$<$ FIGURE 5>}

\subsection{Activity of microbial consortium through electrochemical potential $\left(\mathrm{NAD}^{+} / \mathrm{NADH}\right)$}

Figure 6 a shows three plots of $\mathrm{NAD}^{+} / \mathrm{NADH}$ proportion versus mole fraction of carbonates of feed stocks. The proportional values based on a ratio of molecular composite fed, can allow calculating equilibrium of electrochemical potentials $\psi$ and then this can explain us an interrelationship between thermodynamic driving forces of individual processes. As $x$ is increased, the proportional values are slowly increased and then they become a constant value $\left(8 \times 10^{-4}\right)$ at $x=0.005$. In following high range of $x$, they linearly increase up to $1 \times 10^{-2}$. These results tell us that the $\mathrm{NADH}$ fed is strongly oxidised and the products $\left(\mathrm{NAD}^{+}+\mathrm{H}^{+}+\mathrm{e}^{-}\right.$) can be 
transferred into 'reductive bacteria' requiring the protons and electrons but the activity of the reductive bacteria is relatively decreased as $x$ is increased. In this system, fermentative bacteria and hydrogenophilic methanogens are only reductive bacteria, where the fermentative process by fermentative bacteria, is observed as very strong reductive bacteria in whole BCCU process. Figure $6 \mathrm{~b}$ shows overall equilibrium of electrochemical potentials resulting from the simple faraday calculation of the result in figure 6a. Various electrochemical potentials according to glucose mixture feedstocks, have very low values $(-240<\psi<-210 \mathrm{mV}$ as SHE) and have almost constant values although $x$ is increased. At $x=0.005$, the potentials $\psi$ become a constant value $(-170 \mathrm{mV}$ as SHE) and linearly increase up to $-120 \mathrm{mV}$ as SHE as $x$ is increased. This tells us that biological oxidation and reduction is balanced in the low range of $x$, and then biological oxidation is increased from $x=0.0005$ in high range of $x$. This is directly related to the result of methane yield shown in figure $3 \mathrm{~d}$.

\section{$<$ FIGURE 6>}

Here the authors investigated major driving force of BCCU between proton transport (i.e. $\mathrm{pH}$ ) and electron transport (V). Figure 6c shows the electrochemical potential (V) versus equilibrium $\mathrm{pH}$ value, which is compared with equilibrium of ammonia oxidation (red dotted line) and equilibrium of hydrogenophilic methanogenesis (blue dotted line). As $x$ is increased, $\mathrm{pH}$ value is decreased and the electrochemical potential (V) is almost linearly increased. This means that the proton transport between functional organisms has almost linear relationship with electron transport. Figure 6c also shows that overall equilibria line of the process is slowly deviated from the equilibrium lines as the $\mathrm{pH}$ is decreased, which means that thermodynamic driving force does not increase only for ammonia oxidation but also for acetate oxidisation. However association of ammonium ion with carbonate which may impact the rate of Stickland reaction in proteins [33], is strongly favourable in whole range of $\mathrm{pH}$, but it is limited once water activity is reduced. Once water activity is significantly decreased in low $\mathrm{pH}(<5.8)$, the association of ammonium ion is shifted into favourable dissociation of ammonium bicarbonate and the microbial activity of anaerobic ammonium oxidising bacteria revives significantly in the same low $\mathrm{pH}$ as shown in figure 6c. It tells us that the BCCU in a solid fermentation having very low water content may avoid the ammonia toxicity or inhibition of cell culture by strong anaerobic ammonium oxidation. Empirically the solidification observed in BCCU [10] was explained by the impropriate mixing and or nonhomogeneous solid digestion. 


\section{CONCLUSION}

From the thermodynamic results of biological carbon capture and utilisation,

i) The authors observed that a thermodynamic efficiency of biological carbon capture and utilisation (BCCU) had $32 \%$ of overall reduction in yield of carbon dioxide with compensation of $30 \%$ in yield of methane, while the process was overall endothermic. Total energy ( $\approx 0.33 \mathrm{MJ}$ $\left.\mathrm{1}^{-1}\right)$ was utilised for the carbonate solubility $\left(0.1\right.$ mole $\left.^{-1}\right)$ in batched BCCU.

ii) In unsaturation of carbon dioxide $\left(<0.1\right.$ mole $\left.^{-1}\right)$, the model predicted anaerobic oxidation of ammonium ion, which was significantly reduced to $10 \%$ of ammonium oxidation in a long term operation. This was attributed to association of ammonium (bi)carbonates, which enhanced acetoclastic process from acetoclastic bacteria in hydrogenophilic methanolgenesis and then increased methane formation.

iii) In over-saturation of carbon dioxide $\left(>0.1\right.$ mole $\left.^{-1}\right)$, acetoclastic process was inhibited with hydrogenophilic methanogensesis and then the whole microbial reaction became fermentative in bio-floc. Therefore, a sequenced batch process or two-staged continuous process is thermodynamically suggested in order to improve methane conversion in BCCU.

\section{REFERENCES}

[1] Sally M. Benson, David R. Cole, CO2 Sequestration in Deep Sedimentary Formations, ELEMENTS 4 (2008) 325-331.

[2] DECC, UK Greenhouse Gas Emissions, Provisional Figures and 2012 UK Greenhouse Gas Emissions, Final Figures by Fuel Type and End-User, in: Department of Energy and Climate Change (Ed.) Blue Paper, 2014.

[3] DECC, 2010 to 2015 government policy: greenhouse gas emissions, in: Department of Energy and Climate Change (Ed.) Policy paper, 2015.

[4] M. Keil, S. Whipp, D. Green, Carbon reduction: New challenges for the water industry, New civil engineer (2010).

[5] DEFRA, Future water. The Government's Water Strategy for England, in: Department for Environment Food \& Rural Affairs (Ed.) Blue Paper, 2008.

[6] Sung T. Oh, Jung Rae Kim, Giuliano C. Premier, Tae Ho Lee, Changwon Kim, William T. Sloan, Sustainable wastewater treatment: How might microbial fuel cells contribute, Biotechnology Advances 28 (2010) 871-881. 
[7] Y. Xu, L. Isom, M.A. Hanna, Adding value to carbon dioxide from ethanol fermentations, Bioresour. Technol 101 (2010) 3311-3319.

[8] S. Holloway, Carbon dioxide capture and geological storage, Philos. Trans. Roy. Soc. A Math. Phys. Eng. Sci. 365 (2007) 1095-1107.

[9] R.S. Middleton, J.K. Eccles, The complex future of $\mathrm{CO} 2$ capture and storage: variable electricity generation and fossil fuel power, Appl. Energy 108 (2013) 66-73.

[10] Y. Bajón Fernández, A. Soares, R. Villa, P. Vale, E. Cartmell, Carbon capture and biogas enhancement by carbon dioxide enrichment of anaerobic digesters treating sewage sludge or food waste, Bioresource Technology 159 (2014) 1-7.

[11] C. Salomoni, A. Caputo, M. Bonoli, O. Francioso, M.T. Rodriguez-Estrada, D. Palenzona, Enhanced methane production in a two-phase anaerobic digestion plant, after $\mathrm{CO} 2$ capture and addition to organic wastes, Bioresour. Technol. 102 (2011) 6443-6448.

[12] Y.D. Goswami, F. Kreith, Energy conversion, CRC press2007.

[13] M. Alimahmoodi, C.N. Mulligan, Anaerobic bioconversion of carbon dioxide to biogas in an upflow anaerobic sludge blanket reactor, J. Air Waste Manage. Assoc. 58 (2008) 95-103.

[14] R. Cammack, Advances in inorganic chemistry: Iron-Sulfur proteins, Academic Press Inc. 1992.

[15] Sung T. Oh, Alastair D. Martin, Thermodynamic equilibrium model in anaerobic digestion process, Biochemical Engineering Journal 33 (2007).

[16] Sung T. Oh, Alastair D. Martin, Glucose contents in anaerobic ethanol stillage digestion manipulate thermodynamic driving force in between hydrogenophilic and acetoclastic methanogens, Chemical Engineering Journal 243 (2014) 526-536.

[17] S.S. Ozturk, B.O. Palsson, J. Thiele, J.G. Zeikus, Modelling of interspecies hydrogen transfer in Microbial Flocs, Biotechnology Processes (1987) pp 142-152.

[18] J.H. Thiele, M. Chartrain, J.G. Zeikus, Control of Interspecies Electron Flow during Anaerobic Digestion: Role of Floc Formation in Syntrophic Methanogenesis, Applied and Environ. Microbiol. 54 (1988) pp 10-19.

[19] A. Aguilar, C. Casas, J.M. Lema, Degradation of volatile fatty acids by differently enriched methanogenic cultures: Kinetics and inhibition, Water Research 29 (1995) pp 505-509.

[20] S. Sung, T. Liu, Ammonia inhibition on thermophilic anaerobic digestion, Chemosphere 53 (2003).

[21] M. Pourbaix, Atlas of electrochemical equilibria in aqueous solutions, NACE Cebelcon., New York, 1974.

[22] A.H. Harvey, Semiempirical Correlation for Henry's constants over large temperature ranges, Journal of American Institute Chemical Engineering 42 (1996) pp 1491-1494.

[23] Carl. L. Yaws, Chemical Properties Handbook, 1 ed., McGraw Hill, New York, 1997.

[24] C.L. Yaws, Yaws' Handbook of Thermodynamic and Physical Properties of Chemical Compounds, Knovel2003.

[25] Sung T. Oh, Alastair D. Martin, Long chain fatty acids degradation in anaerobic digester: thermodynamic equilibrium consideration, Process Biochemistry 45 (2010) 335-345.

[26] Sung T. Oh, Alastair. D. Martin, A thermodynamic equilibrium consideration of the effect of sodium ion in acetoclastic methanogenesis, J Chem Technol Biotechnol 88 (2013) 834-844.

[27] W. Stumm, J.J. Morgan, Aquatic Chemistry, John Wiley \& Sons, Inc, New York, 1996.

[28] R. Nakamura, G.J.F. Breedveld, J.M. Prausnitz, Thermodynamic Properties of Gas Mixtures Containing Common Polar and Nonpolar Components, Industrial Engineering Chemical Process Design Division 15 (1976) pp. 557 -564.

[29] Y. Kim, T. Noike, Effect of $\mathrm{CO}_{2}$ partial pressure on the anaerobic digestion Mizu Kankyo Gakkaishi 19 (1996) pp 491-500. 
[30] Y.C. Kim, M.K. Lee, Effects of $\mathrm{P}_{\mathrm{CO} 2}$ on substrate compositions in anaerobic digestion, Hwahak Konghak 36 (1998) pp 78-84.

[31] Sung T. Oh, Alastair D. Martin, Loss of thermodynamic spontaneity in methanogenic consortium with ammonal contents, Chemical engineering journal 243 (2014) 244-253.

[32] Min-Fan Chung, Ko-Jie Chen, Hsiang-Fa Liang, Zi-Xian Liao, Wei-Tso Chia, Younan Xia, Hsing-Wen Sung, A Liposomal System Capable of Generating CO2 Bubbles to Induce Transient Cavitation, Lysosomal Rupturing, and Cell Necrosis, Angewandte Chemie 124 (2012).

[33] D.J. Batstone, J. Keller, I. Angelidaki, S.V. Kalyuzhnyi, S.G. Pavlostathis, A. Rozzi, W.T.M. Sanders, H. Siegrist, V.A. Vavilin, Anaerobic digestion model No.1, IWA publishing, UK, 2002. [34] Shen Weiquan, Yang Shaoli, Feng Xiuli, Lin Lin, Wang Haipeng, Engineering Geology, in: W.S.a.P. Marinos (Ed.) Proceedings of the 30th Interantional Geological Congress, VSP BV, 1997 pp. 226. 